\title{
Complete pathological regression of hepatocellular carcinoma with portal vein thrombosis treated with sorafenib
}

\author{
Sabrina Kermiche-Rahali ${ }^{1}$, Aude Di Fiore ${ }^{2}$, Fanny Drieux ${ }^{3}$, Frédéric Di Fiore ${ }^{2}$, Arnaud François ${ }^{3}$ and Michel Scotté ${ }^{14^{*}}$
}

\begin{abstract}
Sorafenib is a molecular-targeted therapy used in palliative treatment of advanced hepatocellular carcinoma (HCC) in Child-Pugh A patients. We describe the case of a patient who presented with a large HCC in the left liver associated with portal vein thrombosis (PVT). After 9 months of sorafenib treatment, reassessment showed that the tumors had decreased in size with recanalization of the portal vein. A lateral left hepatectomy was performed and pathology showed complete necrosis of the tumor. Sorafenib can downstage HCC in patients with cirrhosis allowing further surgical resection.
\end{abstract}

Keywords: Hepatocellular carcinoma, Sorafenib, Liver resection

\section{Background}

Hepatocellular carcinoma (HCC) is the most common type of primary liver tumor and is the fifth most common malignancy worldwide [1]. Variables related to early HCC status (single tumor $\leq 5 \mathrm{~cm}$ or three nodules $\leq 3$ $\mathrm{cm}$ ), the so-called Milan criteria, define good prognosis and are accessible to curative therapies, such as surgical resection, liver transplantation and percutaneous ablation [2,3]. Surgical resection is still considered the most effective treatment for HCC. However, only $30 \%$ of all patients are diagnosed at early stage and therefore able to benefit from curative therapies [2]. These patients achieve 5-year survival rates of $50 \%$ to $75 \%$ [3].

Most patients are diagnosed at advanced stage. The main prognostic factors are related to tumor status defined by the number and size of nodules, presence or absence of vascular invasion, presence or absence of extrahepatic spread, liver function (Child-Pugh class, serum bilirubin and albumin levels, and portal hypertension), and general health status defined by the Eastern Cooperative Oncology Group (ECOG) classification.

\footnotetext{
* Correspondence: michel.scotte@chu-rouen.fr

${ }^{1}$ Department of Digestive Surgery, Rouen University Hospital, 1 Rue de Germont, 76031 Rouen, France

${ }^{4}$ INSERM U1073, Rouen University Hospital, 1 Rue de Germont, 76031 Rouen, France

Full list of author information is available at the end of the article
}

Untreated patients with advanced-stage disease, that is ECOG performance status grade 1 or grade 2, and/or vascular invasion or extrahepatic spread, have a median survival of 6 to 7 months [4].

Sorafenib (BAY 43-9006, Nexavar; Bayer, Leverkusen, Germany), a multi-target tyrosine kinase inhibitor used in palliative treatment of advanced HCC, can improve the survival of patients [5]. Nevertheless, Llovet et al. [5] demonstrated in a multicenter, phase III, double-blind, placebo-controlled trial that median time to symptomatic progression did not improve, and only $2 \%$ of patients achieved partial radiological response and none complete response. We report the case of a patient with locally advanced HCC associated with portal vein thrombosis (PVT). The patient achieved complete regression of HCC using sorafenib treatment allowing further curative surgical resection.

\section{Case presentation}

A 68-year-old man presented to Rouen University Hospital, Rouen, France, with asthenia, diffuse abdominal pain and cirrhosis. Hepatitis $B$ and $C$ virus serologic status were negative and iron status was normal. Cirrhosis was related to alcohol abuse. Abdominal ultrasound showed hepatomegaly and a liver tumor measuring $14 \mathrm{~cm}$ located in the left lobe. An abdominal computerized tomography (CT) scan confirmed a lesion 

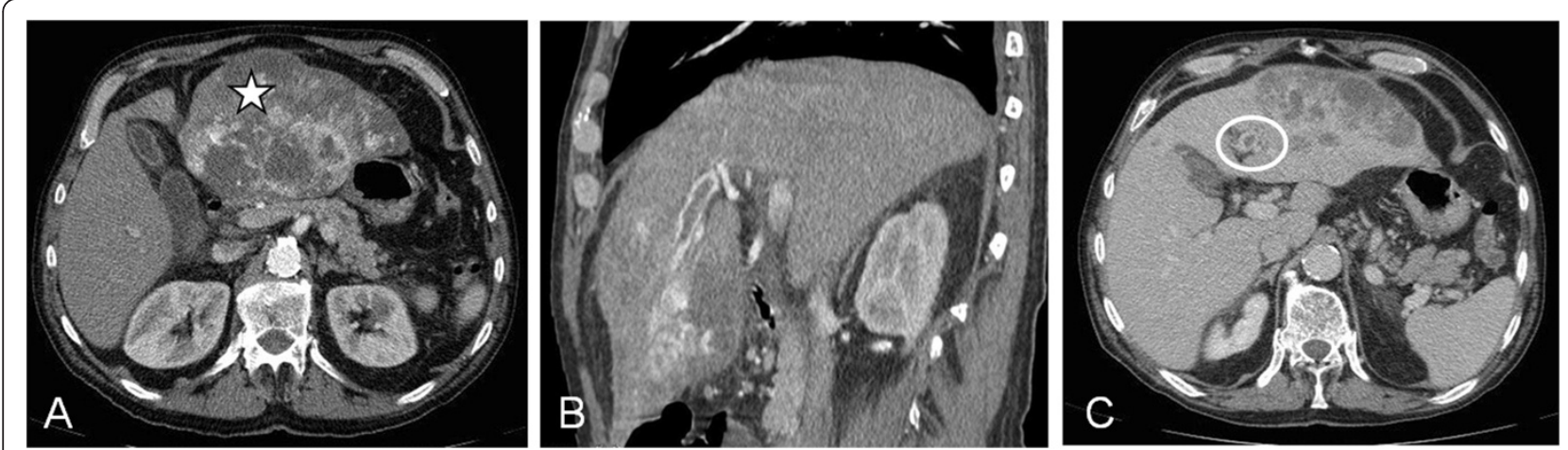

Figure 1 Computerized tomography (CT) scan features of the liver tumor. Liver tumor with (A) arterial enhancement (star), (B) portal washout and (C) portal vein thrombosis (PVT) (circle). CT, computerized tomography; PVT, portal vein thrombosis.

in the left liver measuring $15.7 \mathrm{~cm}$ and with left intrahepatic portal branch thrombosis (Figure 1). Typical radiological features, including hypervascular and portal phase washout, together with an increase in alphafetoprotein (AFP) serum levels at $986 \mathrm{ng} / \mathrm{mL}$ (normal $<20 \mathrm{ng} / \mathrm{mL}$ ), confirmed diagnosis of HCC without performing liver biopsy [2]. The size of the lesion associated with a portal thrombus prohibited curative surgical treatment [3]. Considering the patient's general state of health and the Child-Pugh class (A6), palliative treatment with sorafenib $(800 \mathrm{mg} /$ day $)$ was initiated in January 2011.

After 3 months of treatment, evaluation showed normalization of AFP levels (from $986 \mathrm{ng} / \mathrm{mL}$ to $7 \mathrm{ng}$ / $\mathrm{mL}$ and decrease in hepatic lesion size (from $15.7 \mathrm{~cm}$ to $7 \mathrm{~cm}$ ). Side effects included grade 2 to 3 hand-foot syndrome and diarrhea. Due to this objective radiological response, sorafenib treatment was continued with dose adjustment to $600 \mathrm{mg} /$ day.

After 9 months of treatment, AFP levels decreased to $5.3 \mathrm{ng} / \mathrm{mL}$, and CT scan showed $60 \%$ regression of the hepatic lesion measuring $6 \mathrm{~cm}$ long with recanalization of the left portal branch (Figure 2).
One month after stopping sorafenib, surgical treatment was proposed and a left liver lobectomy was performed without vascular clamping. There were no postsurgical complications and the patient was discharged from hospital 5 days after surgery.

Gross pathological examination showed multiple white nodules and the whole lesion measured $6 \mathrm{~cm} \times 4 \mathrm{~cm} \times$ $5 \mathrm{~cm}$. The nodules were well circumscribed by fibrous tissue. Microscopic examination revealed nodules with a central necrotic core, surrounded by a hyalinized fibrotic capsule. No residual tumor cell was observed. The surrounding liver parenchyma was cirrhotic (METAVIR F4) (Figures 3 and 4). The patient showed no recurrence of HCC 14 months after liver resection.

\section{Discussion}

In this case, a patient with cirrhosis whose HCC was initially unresectable received sorafenib with palliative intent, allowing curative surgical resection. There was no evidence of residual tumor cell at microscopic examination. To our knowledge, only one case of complete pathological response induced by sorafenib treatment in
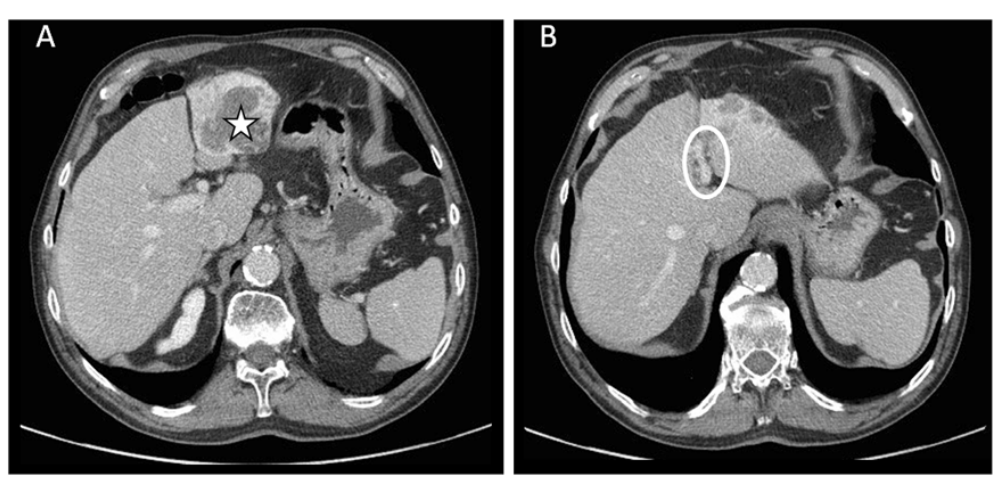

Figure $\mathbf{2}$ Computerized tomography (CT) scan of the left liver tumor lesion after $\mathbf{9}$ months of treatment with sorafenib. (A) Left liver tumor lesion (star), and (B) regression of the lesion with recanalization of the left portal branch (circle). CT, computerized tomography. 


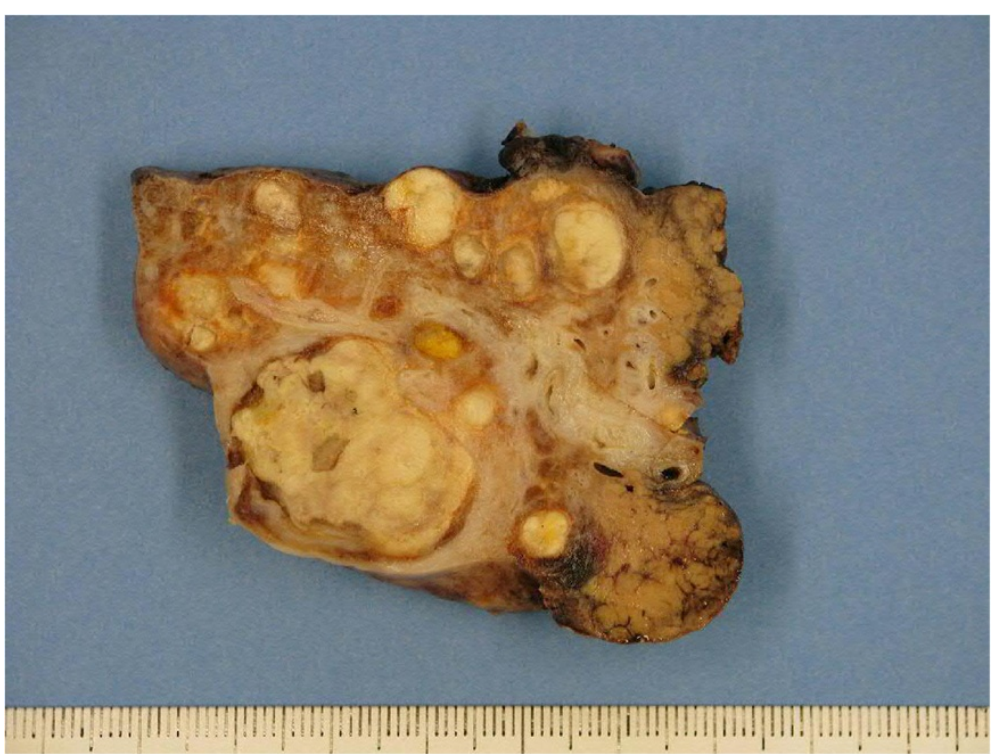

Figure 3 Gross examination of cirrhotic liver parenchyma with multiple white nodules.

a patient with cirrhosis and HCC has been reported in the literature [6].

Diagnostic criteria for $\mathrm{HCC}$ of a cirrhotic liver are mainly biological and radiological. Previously, an algorithm for investigation of liver nodules was proposed by the Barcelona Clinic Liver Cancer (BCLC) Group [7]. Diagnosis depends on the size and radiological characteristics of the nodule, associated with the rate of AFP and, in some cases, biopsy. Subsequently, the strategy for staging and treatment assignment for patients diagnosed with HCC was also proposed by the BCLC Group. In a recent retrospective observational study, Torzilli et al. [8] demonstrated that patients with advanced tumor

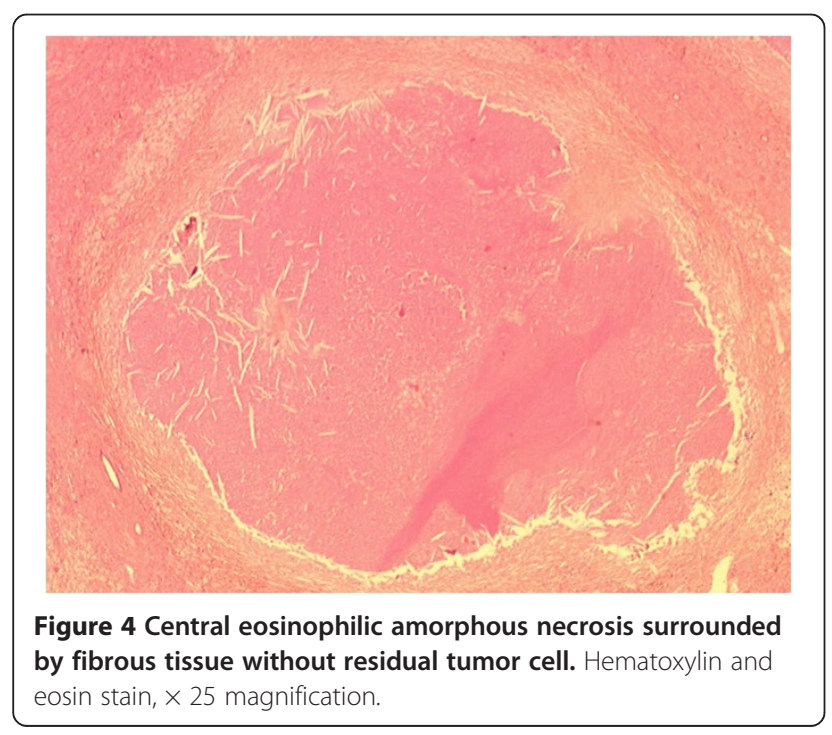

can benefit from surgical resection and suggested that therapeutic guidelines should be updated.

HCC is a hypervascular tumor. Sorafenib is the only multi-kinase inhibitor that blocks receptor tyrosine kinases, such as vascular endothelial growth factor receptor (VEGFR) or platelet-derived growth factor receptor (PDGF-R), and also RAF serine/threonine kinases along the RAF/MEK/ERK pathway [9]. Thus, sorafenib targets both tumor cell proliferation and angiogenesis.

The efficacy of sorafenib in HCC has already been demonstrated in two pivotal, multicenter, phase III, placebo-controlled clinical trials. The SHARP Study Group [5] accrued more than 600 patients with advanced HCC and cirrhosis (Child-Pugh A) not previously treated with any systemic therapy. This study showed for the first time an advantage in terms of median overall survival, which was 10.7 months for sorafenib versus 7.9 months for placebo $(P=0.0006)$. However, median time to symptomatic progression did not differ significantly between the sorafenib and placebo group (4.1 months and 4.9 months, respectively; $P=0.77)$. In fact, only seven patients $(2 \%)$ treated with sorafenib were considered responders according to Response Evaluation Criteria In Solid Tumors (RECIST) criteria. No complete response was recorded. Similarly, the second phase III clinical study, carried out in the Asia-Pacific region [10], recruited and randomized a total of 226 patients in a 2:1 fashion. Median overall survival of patients in the sorafenib group was 6.2 months, which was significantly better than the 4.1 months achieved in the placebo group $(P=0.0155)$. In the analysis of best response, five of 150 patients in the 
sorafenib group (3.3\%) achieved partial response. There was also no complete response.

Despite the demonstrated effectiveness of sorafenib, there are few reported cases of resection in patients with biological or radiological response. Irtan et al. [11] reported two cases of downstaging of locally advanced HCC after sorafenib treatment, allowing curative resection with complete pathological response. However, in neither of these cases was the nontumoral liver cirrhotic. Both patients developed chronic liver disease (METAVIR F3) due to hemochromatosis and hepatitis B. The Barbier et al. study [12] described two other cases of surgery after sorafenib in two patients with chronic disease due to hepatitis $C$ and chronic alcoholism, respectively. Nevertheless, histopathological examination found $35 \%$ and $60 \%$ of tumor necrosis, along with residual tumor cell, respectively. To our knowledge, only one case report of complete pathological regression in severe chronic liver disease (METAVIR F4) has been reported in the literature [6]. No tumor cells were found and recanalization of the portal vein was complete.

Recanalization of the portal vein is another interesting point. PVT is now considered as the main negative prognostic factor in patients with HCC. HCC with malignant PVT has poor prognosis, thus prohibiting curative approaches. In contrast, benign (fibrin clot) PVT is not a contraindication to curative treatment. Patients with cirrhosis and HCC may develop either benign or malignant PVT. In this context, critical evaluation of PVT by imaging techniques and diagnostic criteria [13] is mandatory to differentiate benign and malignant PVT [14]. In these settings, Li et al. [15] recently suggested that vascular endothelial growth factor may play a pivotal role in HCC angiogenesis, and in PVT onset and evolution. Sorafenib could exert a beneficial effect on PVT by inhibiting the VEGFR pathway.

\section{Conclusions}

Sorafenib opens a new window for treatment of locally advanced HCC and highlights the importance of identifying factors that could be associated with good response to this therapy. However, complete tumor regression and necrosis increase difficulties in both tissue analysis and search for predictive factors of good response to the tumor (tumor phenotypes, biological markers, and so on). Furthermore, close monitoring and regular reassessment of patients is mandatory, in order to promptly identify good responders to sorafenib and subsequently propose surgical treatment or other curative treatment. Moreover, although a small number of hepatic resections following sorafenib administration have been reported, no intraoperative or postoperative complications related to preoperative treatment have been observed [16].
Therefore, our case report suggests that neoadjuvant sorafenib treatment could be a relay to surgery in selected patients.

\section{Consent}

Written informed consent was obtained from the patient for publication of this case report and any accompanying images. A copy of the written consent is available for review by the Editor-in-Chief of this journal.

\section{Abbreviations}

AFP: Alpha-fetoprotein; BCLC: Barcelona Clinic Liver Cancer; CT: Computerized tomography; ECOG: Eastern Cooperative Oncology Group;

HCC: Hepatocellular carcinoma; PDGF-R: Platelet-derived growth factor receptor; PVT: Portal vein thrombosis; RECIST: Response Evaluation Criteria In Solid Tumors; VEGFR: Vascular endothelial growth factor receptor.

\section{Competing interests}

The authors declare that they have no competing interests.

\section{Authors' contributions}

SKR and MS did operate on the patient, analysed and interpreted data and wrote the manuscript. AdF and FdF have treated the patient with sorafenib and participated to followup FD and AF performed the pathological analysis. All authors read and approved the final manuscript.

\section{Acknowledgments}

We are grateful to Nikki Sabourin-Gibbs, Rouen University Hospital, Rouen, France, for editing the manuscript.

\section{Author details}

'Department of Digestive Surgery, Rouen University Hospital, 1 Rue de Germont, 76031 Rouen, France. ${ }^{2}$ Department of Hepatology and Gastroenterology, Rouen University Hospital, 1 Rue de Germont, 76031 Rouen, France. ${ }^{3}$ Department of Pathology, Rouen University Hospital, 1 Rue de Germont, 76031 Rouen, France. ${ }^{4}$ INSERM U1073, Rouen University Hospital, 1 Rue de Germont, 76031 Rouen, France.

Received: 14 May 2013 Accepted: 27 July 2013

Published: 2 August 2013

\section{References}

1. Llovet JM, Burroughs A, Bruix J: Hepatocellular carcinoma. Lancet 2003, 362:1907-1917.

2. Bruix J, Sherman M, Llovet JM, Beaugrand M, Lencioni R, Burroughs AK, Christensen E, Pagliaro L, Colombo M, Rodés J, EASL Panel of Experts on HCC: Clinical management of hepatocellular carcinoma. Conclusions of the Barcelona-2000 EASL conference. European Association for the Study of the Liver. I Hepatol 2001, 35:421-430.

3. Bruix J, Llovet JM: Prognostic prediction and treatment strategy in hepatocellular carcinoma. Hepatology 2002, 35:519-524.

4. Llovet JM, Di Bisceglie AM, Bruix J, Kramer BS, Lencioni R, Zhu AX, Sherman M, Schwartz M, Lotze M, Talwalkar J, Gores GJ, Panel of Experts in HCCDesign Clinical Trials: Design and endpoints of clinical trials in hepatocellular carcinoma. J Natl Cancer Inst 2008, 100:698-711.

5. Llovet JM, Ricci S, Mazzaferro V, Hilgard P, Gane E, Blanc JF, de Oliveira AC, Santoro A, Raoul JL, Forner A, Schwartz M, Porta C, Zeuzem S, Bolondi L, Greten TF, Galle PR, Seitz JF, Borbath I, Häussinger D, Giannaris T, Shan M, Moscovici M, Voliotis D, Bruix J, SHARP Investigators Study Group: Sorafenib in advanced hepatocellular carcinoma. N Engl J Med 2008, 359:378-390.

6. Curtit E, Thiery-Vuillemin A, Nguyen T, Heyd B, Pivot X, Di Martino V, Borg C: Complete histologic response induced by sorafenib in advanced hepatocellular carcinoma: a case report. J Clin Oncol 2011, 20:330-332.

7. Bruix J, Sherman M, Practice Guidelines Committee, American Association for the Study of Liver Diseases: Management of hepatocellular carcinoma. Hepatology 2005, 42:1208-1236.

8. Torzilli G, Belghiti J, Kokudo N, Takayama T, Capussotti L, Nuzzo G, Vauthey JN, Choti MA, De Santibanes E, Donadon M, Morenghi E, Makuuchi M: A snapshot of the effective indications and results of surgery for 
hepatocellular carcinoma in tertiary referral centers: is it adherent to the EASL/AASLD recommendations?: an observational study of the HCC East-west study group. Ann Surg 2013, 257:929-937.

9. Wilhelm SM, Carter C, Tang L, Wilkie D, McNabola A, Rong H, Chen C, Zhang X, Vincent P, McHugh M, Cao Y, Shujath J, Gawlak S, Eveleigh D, Rowley B, Liu L, Adnane L, Lynch M, Auclair D, Taylor I, Gedrich R, Voznesensky A, Riedl B, Post LE, Bollag G, Trail PA: BAY 43-9006 exhibits broad spectrum oral antitumor activity and targets the RAF/MEK/ERK pathway and receptor tyrosine kinases involved in tumour progression and angiogenesis. Cancer Res 2004, 64:7099-7109.

10. Cheng AL, Kang YK, Chen Z, Tsao CJ, Qin S, Kim JS, Luo R, Feng J, Ye S, Yang TS, Xu J, Sun Y, Liang H, Liu J, Wang J, Tak WY, Pan H, Burock K, Zou J, Voliotis D, Guan Z: Efficacy and safety of sorafenib in patients in the AsiaPacific region with advanced hepatocellular carcinoma: a phase III randomised, double-blind, placebo-controlled trial. Lancet Oncol 2009, 10:25-34.

11. Irtan S, Chopin-Laly X, Ronot M, Faivre S, Paradis V, Belghiti J: Complete regression of locally advanced hepatocellular carcinoma induced by sorafenib allowing curative resection. Liver Int 2011, 31:740-743.

12. Barbier L, Muscari F, Le Guellec S, Pariente A, Otal P, Suc B: Liver resection after downstaging hepatocellular carcinoma with sorafenib. Int I Hepatol 2011, 2011:7910-7913.

13. Tarantino L, Francica G, Sordelli I, Esposito F, Giorgio A, Sorrentino P, de Stefano G, Di Sarno A, Ferraioli G, Sperlongano P: Diagnosis of benign and malignant portal vein thrombosis in cirrhotic patients with hepatocellular carcinoma: color Doppler US, contrast-enhanced US, and fine needle biopsy. Abdom Imaging 2006, 31:537-544.

14. Piscaglia F, Gianstefani A, Ravaioli M, Golfieri R, Cappelli A, Giampalma E, Sagrini E, Imbriaco G, Pinna AD, Bolondi L, Bologna Liver Transplant Group: Criteria for diagnosing benign portal vein thrombosis in the assessment of patients with cirrhosis and hepatocellular carcinoma for liver transplantation. Liver Transp/ 2010, 16:658-667.

15. Li Q, Xu B, Fu L, Hao XS: Correlation of four vascular specific growth factors with carcinogenesis and portal vein tumor thrombus formation in human hepatocellular carcinoma. J Exp Clin Cancer Res 2006, 25:403-409.

16. Barbier L, Fuks D, Pessaux P, Muscari F, Le Treut YP, Faivre S, Belghiti J: Safety of liver resection for hepatocellular carcinoma after sorafenib therapy: a multicenter case-matched study. Ann Surg Oncol 2013. doi:10.1245/s10434-013-3029-z.

doi:10.1186/1477-7819-11-171

Cite this article as: Kermiche-Rahali et al:: Complete pathological regression of hepatocellular carcinoma with portal vein thrombosis treated with sorafenib. World Journal of Surgical Oncology 2013 11:171.

\section{Submit your next manuscript to BioMed Central and take full advantage of:}

- Convenient online submission

- Thorough peer review

- No space constraints or color figure charges

- Immediate publication on acceptance

- Inclusion in PubMed, CAS, Scopus and Google Scholar

- Research which is freely available for redistribution 